\title{
Somatosensory Temporal Discrimination Threshold Involves Inhibitory Mechanisms in the Primary Somatosensory Area
}

\author{
Lorenzo Rocchi, ${ }^{1,2}$ Elias Casula, ${ }^{1,3}$ Pierluigi Tocco, ${ }^{1,4}{ }^{-}$Alfredo Berardelli, ${ }^{2,5}$ and John Rothwell ${ }^{1}$ \\ ${ }^{1}$ Sobell Department of Motor Neuroscience and Movement Disorders, Institute of Neurology, University College London, WC1N 3BG, London, United \\ Kingdom, ${ }^{2}$ Department of Neurology and Psychiatry, Sapienza University of Rome, 00185 Rome, Italy, ${ }^{3}$ Non-Invasive Brain Stimulation Unit, Clinical and \\ Behavioral Neurology Department, Institute for Inpatient Treatment and Scientific Studies Santa Lucia Foundation, 00142 Rome, Italy, ${ }^{4}$ Department of \\ Neurological and Movement Sciences, University of Verona, 37134 Verona, Italy, and ${ }^{5}$ Institute for Inpatient Treatment and Scientific Studies Neuromed \\ Institute, 86077 Pozzilli, Italy
}

\begin{abstract}
Somatosensory temporal discrimination threshold (STDT) is defined as the shortest time interval necessary for a pair of tactile stimuli to be perceived as separate. Although STDT is altered in several neurological disorders, its neural bases are not entirely clear. We used continuous theta burst stimulation (cTBS) to condition the excitability of the primary somatosensory cortex in healthy humans to examine its possible contribution to STDT. Excitability was assessed using the recovery cycle of the N20 component of somatosensory evoked potentials (SEP) and the area of high-frequency oscillations (HFO). cTBS increased STDT and reduced inhibition in the N20 recovery cycle at an interstimulus interval of $5 \mathrm{~ms}$. It also reduced the amplitude of late HFO. All three effects were correlated. There was no effect of cTBS over the secondary somatosensory cortex on STDT, although it reduced the N120 component of the SEP. STDT is assessed conventionally with a simple ascending method. To increase insight into the effect of cTBS, we measured temporal discrimination with a psychophysical method. cTBS reduced the slope of the discrimination curve, consistent with a reduction of the quality of sensory information caused by an increase in noise. We hypothesize that cTBS reduces the effectiveness of inhibitory interactions normally used to sharpen temporal processing of sensory inputs. This reduction in discriminability of sensory input is equivalent to adding neural noise to the signal.
\end{abstract}

Key words: high-frequency oscillations; somatosensory evoked potentials; somatosensory temporal discrimination threshold; transcranial magnetic stimulation

\section{Significance Statement}

Precise timing of sensory information is crucial for nearly every aspect of human perception and behavior. One way to assess the ability to analyze temporal information in the somatosensory domain is to measure the somatosensory temporal discrimination threshold (STDT), defined as the shortest time interval necessary for a pair of tactile stimuli to be perceived as separate. In this study, we found that STDT depends on inhibitory mechanisms within the primary somatosensory area (S1). This finding helps interpret the sensory processing deficits in neurological diseases, such as focal dystonia and Parkinson's disease, and possibly prompts future studies using neurostimulation techniques over S1 for therapeutic purposes in dystonic patients.

\section{Introduction}

Somatosensory temporal discrimination threshold (STDT) is defined as the shortest time interval necessary for a pair of tactile

Received May 21, 2015; revised Nov. 4, 2015; accepted Nov. 12, 2015.

Author contributions: L.R., A.B., and J.R. designed research; L.R., E.C., and P.T. performed research; L.R. and E.C. analyzed data; L.R., E.C., P.T., A.B., and J.R. wrote the paper.

The authors declare no competing financial interests.

Correspondence should be addressed to Dr. Lorenzo Rocchi, Sobell Department of Motor Neuroscience and Movement Disorders, Institute of Neurology, University College London, WC1N 3BG, London, UK. E-mail: rocchi.lor@gmail.com. stimuli to be perceived as separate (Lacruz et al., 1991; Conte et al., 2012). Clinically, it is usually assessed with a simple ascending protocol in which gradually increasing intervals are presented and STDT is taken as the time when three consecutive pairs are identified correctly. Estimated in this way, STDT is impaired in several basal ganglia disorders, including dystonia (Tamura et al., 2008; Scontrini et al., 2009; Conte et al., 2014), Parkinson's dis- 
ease (Artieda et al., 1992; Conte et al., 2010, 2013), and multiple system atrophy (Rocchi et al., 2013). Work on healthy subjects (Pastor et al., 2004; Conte et al., 2012) and on patients with focal cerebral lesions (Lacruz et al., 1991) has shown that several brain regions are involved in STDT, such as the primary somatosensory area (S1), the presupplementary motor area, and the basal ganglia. However, the precise contribution of each area to the task is unknown. In the present study, we ask whether S1 or the secondary somatosensory cortex (S2) act purely to transmit the sensory information to other centers or whether they are involved in some form of active processing of the signal that contributes to STDT. Conte et al. (2012) have shown that continuous theta burst (cTBS) transcranial magnetic stimulation (TMS), a technique that can interfere with the function of cortical areas, increases STDT in healthy subjects (Conte et al., 2012). Therefore, we applied it to S1 and S2 to test whether changes in STDT were correlated with changes in physiological processing in each area.

Because cTBS is known to reduce the excitability of inhibitory systems in primary motor cortex (M1), we tested whether this might also be the case in S1 (Conte et al., 2012). The activity of inhibitory interneurons in $\mathrm{S} 1$ can be probed by measuring high-frequency oscillations (HFO), which are low-amplitude, high-frequency wavelets superimposed on the N20 wave of somatosensory evoked potentials (SEP) and represent, at least in their late component, the activity of S1 inhibitory interneurons (Curio, 2000; Ozaki and Hashimoto, 2011). Another marker of S1 inhibition is thought to be the recovery cycle of SEP. Using paired-pulse stimulation (PP-SEP), the amplitude of the SEP evoked by the second stimulus is suppressed depending on the interstimulus interval (ISI; Valeriani et al., 2005; Vollono et al., 2010).

The role of higher-order somatosensory areas in STDT has not been investigated. In particular, neurons in S2 show spiking rate modulation based on the frequency of tactile stimuli (Salinas et al., 2000). S2 has also been showed to be involved in a vibrotactile sequential discrimination task (Romo et al., 2002; Romo and Salinas, 2003); thus, a role of S2 in STDT may be hypothesized, although it has not yet been verified experimentally. In S2, we recorded late components of the SEP.

Our hypothesis was that, if cTBS reduced the effectiveness of inhibitory systems in S1 that were involved in temporal sharpening of sensory inputs, this would be equivalent to reducing the discriminability of paired inputs. To test this, in a final experiment, we examined STDT using a psychophysical method with the prediction that reducing the quality of sensory information would decrease the slope of the discrimination curve.

\section{Materials and Methods}

\section{Subjects}

Twenty-two healthy subjects ( 12 males, 10 females, aged $29.24 \pm 4.32$ years), all right-handed (Oldfield, 1971), were enrolled in the study. Participants had no history of any neuropsychiatric disorders, neurosurgery, or metal or electronic implants and were not taking drugs with actions on the CNS level at the time of the experiments. All experimental procedures were approved by the local institutional review board and conducted in accordance with the Declaration of Helsinki and according to international safety guidelines. The same 12 subjects took part in Experiments $1-3$, whereas the other 10 subjects participated in Experiments 4 and 5 (see below).

\section{STDT}

Ascending method. In Experiments 1-3, STDT was investigated by delivering paired stimuli starting with an ISI of $0 \mathrm{~ms}$ (simultaneous pair) and progressively increasing the ISI steps by $10 \mathrm{~ms}$, using the experimental procedure of Conte et al. $(2010,2012)$. Paired tactile stimuli consisted of square-wave electrical pulses delivered with a constant-current stimulator (Digitimer DS7A) through surface skin electrodes with the anode located $0.5 \mathrm{~cm}$ distally to the cathode. The surface skin electrodes were applied on the distal phalanx of both the left and right index fingers. The stimulation intensity was defined for each subject by delivering series of stimuli at an increasing intensity from $2 \mathrm{~mA}$ in steps of $0.5 \mathrm{~mA}$; the intensity used for the STDT was the minimal intensity perceived by the subject in 10 of 10 consecutive stimuli (Conte et al., 2010, 2012). Before STDT testing started, subjects familiarized themselves with the task and achieved a stable performance. Subjects were asked to report verbally whether they perceived a single stimulus or two temporally separate stimuli. The first of three consecutive ISI at which participants recognized the stimuli as temporally separated was considered the STDT. To keep the subject's attention level constant during the test and to minimize the risk of perseverative responses, the STDT testing procedure included "catch" trials consisting of a single stimulus delivered randomly. Each session comprised four separate blocks. The STDT was defined as the average of four STDT values (i.e., one for each block) and was entered in the data analysis.

Psychophysical method. In Experiments 4 and 5, subjects underwent a choice reaction time (RT) task in which they had to use their right hand to press a button to indicate that they perceived a single stimulus or another button when they perceived two stimuli; electrical pulses were applied on the distal phalanx of the left index finger. Fifteen ISI were investigated (from 0 to $140 \mathrm{~ms}$ ), and 15 trials for each ISI were delivered in a random order. The number of " 1 " and " 2 " responses for each ISI were measured. A psychometric curve was created plotting the percentage of " 2 " responses as a function of the ISI. A logistic function was fitted to the data. The psychophysical relative threshold (PRT), which is a measure of the amount of change that a stimulus must have to be detected by the subject, was defined as half of the difference in ISI measured at $0.75 p$ and $0.25 p$, where $p$ indicates percentage on the $Y$-axis. The point of subjective equality (PSE), which is a measure of the internal boundary used to classify the two examined categories (one or two perceived stimuli), was calculated as the ISI corresponding to $0.5 \mathrm{p}$ in the psychometric curve (Mendez et al., 2011). Finally, average RTs were measured for each ISI and analyzed.

\section{SEP recording and analysis}

SEP were recorded from scalp $\mathrm{Ag}-\mathrm{AgCl}$ surface electrodes. In Experiments 1 and 3, the active electrode was placed at CP4 and the reference electrode at $\mathrm{Fz}$, according to the international 10-20 system of EEG electrode placement (Klem et al., 1999). The left median nerve was stimulated at the wrist with a constant-current stimulator (Digitimer DS7A), with the anode placed on the wrist crease and the cathode placed $2 \mathrm{~cm}$ proximal. Monophasic square wave pulses of $200 \mu$ s duration were delivered at $250 \%$ of the sensory threshold and at a frequency of $5 \mathrm{~Hz}$. Recordings were collected at a sampling rate of $5 \mathrm{kHz}$, beginning $20 \mathrm{~ms}$ before each stimulus and lasting for $100 \mathrm{~ms}$. Data were band-passed filtered from $3 \mathrm{~Hz}$ to $2 \mathrm{kHz}$ (Cruccu et al., 2008). In the first block, 1000 sweeps were averaged, and N20 peak latency and N20-P25 peak-to-peak amplitude were measured. The recording from this block was also used to measure HFO, as explained below. Three more recording blocks of 750 frames each were performed to measure the N20-P25 recovery cycle. In each of them, 750 trials were averaged, and paired pulses at ISI of 5, 20, and $40 \mathrm{~ms}$ were delivered (Meyer-Hardting et al., 1983; Valeriani et al., 2005; Vollono et al., 2010). In the paired stimuli trials, the responses after the second stimulus were obtained by subtracting the SEP waveform obtained by the first stimulus (Meyer-Hardting et al., 1983; Valeriani et al., 2005; Vollono et al., 2010). R5, R20, and R40 were defined as the ratio between the second and first responses.

In Experiment 2, SEP were recorded in a manner similar to Experiment 1, but active electrodes were placed at T3 and T4 with an Fz reference. A stimulation frequency of $1.2 \pm 20 \% / \mathrm{s}$ was used with a sweep duration of $300 \mathrm{~ms}$, including a $40 \mathrm{~ms}$ period before the stimulus artifact. A single block of 250 frames was recorded, so as to obtain a clear N120 component on the temporal region contralateral to stimulation (T4; 
García-Larrea et al., 1995; Valeriani et al., 2003). N120 latency and amplitude baseline to peak were measured.

\section{Analysis of HFO}

To extract HFO from the underlying N20, the stimulus artifact was removed manually from -10 to $+5 \mathrm{~ms}$ to avoid ringing (Katayama et al., 2010). The SEP wide-band signal was bandpass filtered digitally (400$800 \mathrm{~Hz}$ ) and averaged. HFO waveform was divided in two components, namely early (e-HFO) and late (l-HFO), separated by the latency of the N20 peak. Onset of e-HFO and offset of 1-HFO were defined as the time point at which their amplitudes exceeded the averaged background noise level by 3 SDs (Murakami et al., 2008); the signal was then corrected for DC shift and rectified. e-HFO and 1-HFO area under the curve were measured and analyzed.

\section{TMS and electromyographic recording}

EMG activity was recorded through a pair of $\mathrm{Ag} / \mathrm{AgCl}$ electrodes placed over the left first dorsal interosseous (FDI) muscle in a belly-tendon manner. Raw signal, sampled at $5 \mathrm{kHz}$ with a CED 1401 analog-to-digital laboratory interface (Cambridge Electronic Design), was amplified and filtered (bandwidth, $20 \mathrm{~Hz}$ to $2 \mathrm{kHz}$ ) with a Digitimer D360 (Digitimer). Data were stored on a laboratory computer for online visual display and additional offline analysis (Signal software; Cambridge Electronic Design). To ensure complete target muscle relaxation throughout the experimental sessions, we continuously monitored the EMG activity with audio and high-gain visual feedback.

Single-pulse TMS was performed using a Magstim 200 stimulator with a $70 \mathrm{~mm}$ figure-of-eight coil (Magstim) that produces stimuli with a monophasic waveform and pulse width $\sim 0.1 \mathrm{~ms}$. Repetitive TMS, required for cTBS, was delivered with a biphasic Magstim Rapid ${ }^{2}$ stimulator. cTBS was delivered to the right S1 and the right S2 according to the procedures described in the next paragraph. Three-pulse bursts at $50 \mathrm{~Hz}$ repeated every $200 \mathrm{~ms}$ for $40 \mathrm{~s}$ were delivered at $80 \%$ active motor threshold (AMT; Huang et al., 2005). AMT was calculated during a $10-15 \%$ maximum voluntary contraction of the right FDI as the lowest magnetic stimulator intensity able to evoke a motor evoked potential (MEP) of at least $200 \mu \mathrm{V}$ in 5 of 10 consecutive trials. The motor hotspot was defined as the M1 site at which TMS evoked the largest MEP in the FDI muscle. In Experiment 3, as a control condition for Experiment 1, sham cTBS was applied to the right $\mathrm{S}$, with the coil held perpendicularly to the scalp surface (Conte et al., 2014).

\section{Localization of cortical areas of interest}

To ensure accurate coil positioning during cTBS, we used a neuronavigator Polaris Spectra optical measurement system (Northern Digital) combined with Brainsight navigation software (Rogue Research). An estimated individualized MRI scan in the Talairach space was used for all the participants. Previous studies demonstrated that the mean accuracy of the estimated MRI scans is comparable with the spatial resolution of TMS (Herwig et al., 2001; Sandrini et al., 2008). S1 and S2 were located according to Talairach coordinates reported in previous studies, respectively $(x, y, z)=(48,-28,54)$ for right $S 1$ (Boakye et al., 2000) and $(x, y, z)=(52,-4,18)$ for S2 (Lockwood et al., 2013).

\section{Procedure}

In Experiment 1, STDT, PP-SEP, and HFO were measured before cTBS (T0), 5 min after cTBS (T1), and $30 \mathrm{~min}$ after cTBS (T2) on S1. In Experiment 2, STDT and SEP from S2 were measured before cTBS (T0), 5 min after cTBS (T1), and $30 \mathrm{~min}$ after cTBS (T2) delivered over S2. Experiment 3 was conducted similarly to the first session, although sham cTBS was used. The same 12 subjects participated in the first three experiments. The three sessions were counterbalanced across subjects, and STDT and the different blocks of SEP recordings were randomized within each session. At least 1 week elapsed between each session. In Experiment 4, we assessed STDT with the psychophysical method, as well as the ascending method before cTBS (T0) and 5 min after cTBS (T1). Experiment 5 was similar to Experiment 4, except that sham cTBS was used. The same 10 subjects participated in Experiments 4 and 5.

\section{Statistical analysis}

A three-way repeated-measures ANOVA with session (S1, S2, sham), time (T0, T1, T2), and side (right, left) as factors of analysis was performed to disclose possible differences of STDT values at baseline and to evaluate the effect of cTBS on STDT in Experiments 1 to 3. Two separate two-way repeated-measures ANOVAs with session ( $\mathrm{S} 1$, sham) and time (T0, T1, T2) as factors of analysis were performed to disclose possible effects of cTBS on N20 amplitude and latency. A three-way repeatedmeasures ANOVA with session (S1, sham), time (T0, T1, T2), and ISI (R5, R20, R40) as factors of analysis was performed to investigate the effect of cTBS on N20 recovery cycle. Two separate two-way repeatedmeasures ANOVAs with session (S1, sham) and time (T0, T1, T2) as factors of analysis were performed to investigate the effect of cTBS on e-HFO and 1-HFO area. Pearson's correlation coefficient was used to investigate possible correlations between baseline STDT measured on left hand, e-HFO area, l-HFO, and SEP recovery cycle. The same test was used to investigate whether the changes induced by cTBS on the same parameters from $\mathrm{T} 0$ and $\mathrm{T} 1$ and from $\mathrm{T} 0$ and $\mathrm{T} 2$ were correlated. A two-way repeated-measures ANOVA with time (T0, T1, T2) and electrode (T4, T3) as factors of analysis was performed to disclose a possible effect of cTBS delivered over S2 on the N120 amplitude. Two separate two-way repeated-measures ANOVAs with session (real, sham) and time (T0, T1) as factors of analysis were performed to disclose possible changes induced by cTBS on PRT and PSE. A three-way repeatedmeasures ANOVA with session (real, sham), time (T0, T1), and ISI (0$140 \mathrm{~ms}$ ) as factors of analysis was performed to investigate a possible effect of cTBS on RT. A three-way repeated-measures ANOVA with session (real, sham), time (T0, T1), and side (right, left) as factors of analysis was performed to disclose possible effects on STDT measured with the ascending method in Experiments 4 and 5. An additional Pearson's correlation coefficient was used to investigate a possible correlation between baseline values of STDT, PSE, and PRT measured in Experiment 4.

Before undergoing ANOVA procedures, normal distribution of data was assessed by means of Shapiro-Wilks test. All $p$ values $<0.05$ were considered significant. Greenhouse- Geisser correction was used when necessary to correct for nonsphericity (i.e., Mauchly's test $<0.05$ ). Bonferroni's post hoc test was used for all post hoc analyses. Bonferroni's correction for multiple comparisons was applied when needed.

\section{Results}

In summary, cTBS over S1 increased STDT in the contralateral hand (from $50.27 \mathrm{~ms}$ at T0, to $75.56 \mathrm{~ms}$ at $\mathrm{T} 1$ and $60.27 \mathrm{~ms}$ at T2). This was probably attributable to an increase in the noise of the system, as suggested by the increase in PRT (from 8.96 to 21.26 ms) and RT (see Fig. 3). cTBS over S1 also decreased the amplitude of $\mathrm{N} 20$ (from $2.95 \mu \mathrm{V}$ at T0 to $2.18 \mu \mathrm{V}$ at T1 and 2.61 at T2) and decreased the effectiveness of inhibition in S1 probed with the PP-SEP protocol at 5 ms ISI (see Fig. 5), whereas N20 latency (19.26 ms at T0) was unchanged. 1-HFO were decreased in amplitude after cTBS over S1 (from $3.22 \times 10^{-4} \mu \mathrm{V}^{2}$ at T0 to $2.05 \times$ $10^{-4} \mu \mathrm{V}^{2}$ at $\mathrm{T} 1$ and $2.64 \mu \mathrm{V}^{2}$ at T2), whereas e-HFO were increased (from $2.96 \times 10^{-4} \mu \mathrm{V}^{2}$ at T0 to $3.73 \times 10^{-4} \mu \mathrm{V}^{2}$ at T1 and $3.22 \mu \mathrm{V}^{2}$ at T2). Changes in STDT, PP-SEP at $5 \mathrm{~ms} \mathrm{ISI,} \mathrm{and}$ 1-HFO were correlated. cTBS over S2 decreased N120 amplitude (from $2.31 \mu \mathrm{V}$ at $\mathrm{T} 0$ to $1.81 \mu \mathrm{V}$ at $\mathrm{T} 1$ and $2.08 \mu \mathrm{V}$ at T2), but it left STDT unchanged.

\section{STDT}

Ascending method

As reported previously (Conte et al., 2012), cTBS over S1 transiently increased STDT measured with the ascending method in the contralateral but not ipsilateral hand (Fig. 1). There was no effect after cTBS over S2.

This was confirmed in the statistical analysis. The three-way ANOVA on the STDT data obtained in Experiments 1 to 3 (Fig. 1) showed a significant main effect of session $\left(F_{(2,22)}=7.989\right.$; 


\section{STDT}

\section{LEFT}
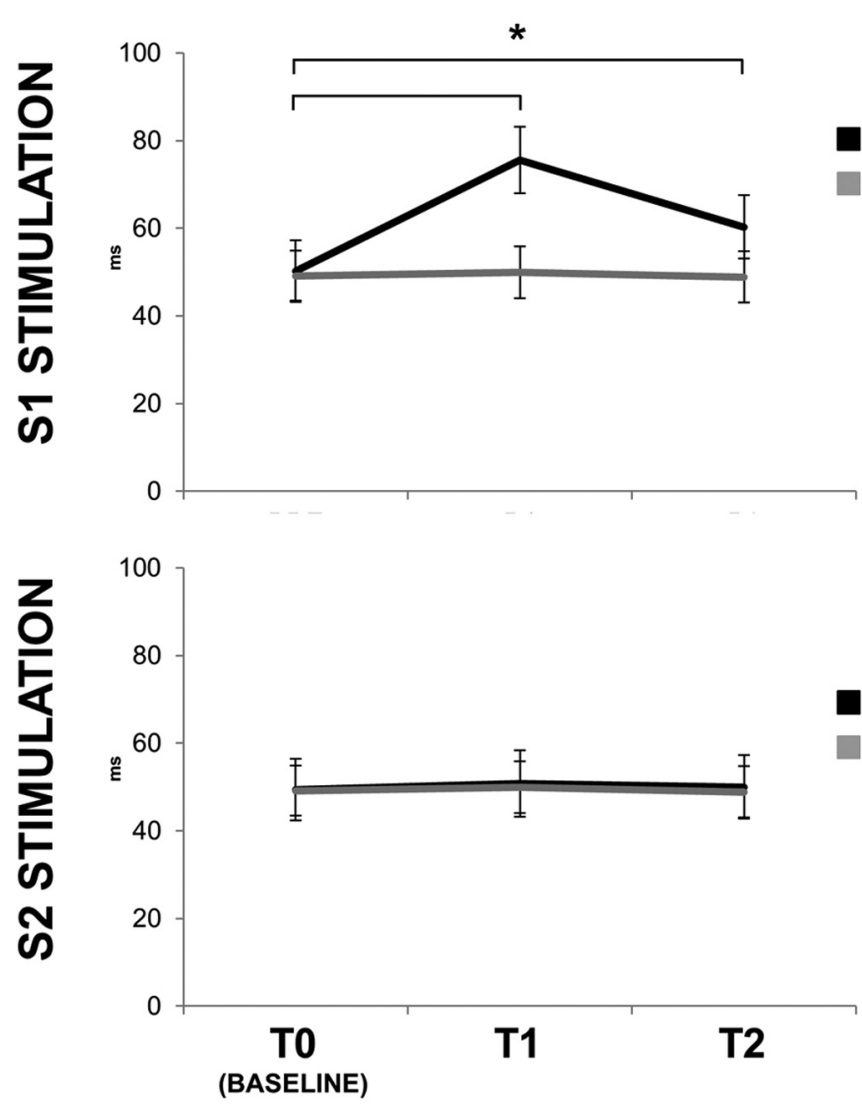

\section{RIGHT}

\section{S1-cTBS \\ Sham}

S2-cTBS

Sham
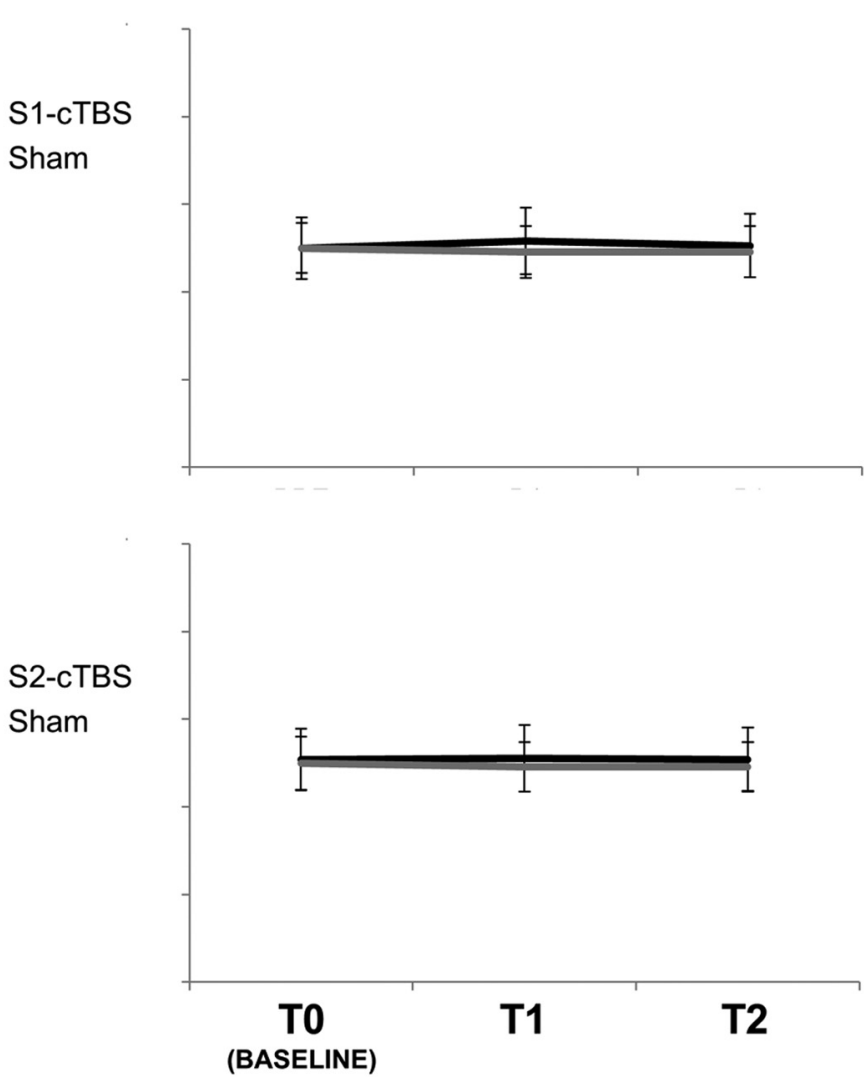

Figure 1. STDT values for the left (left column) and right (right column) index finger before (T0), immediately after (T1), and $30 \mathrm{~min}$ after (T2) real (black lines) and sham (gray lines) cTBS over S1 (top row) and S2 (bottom row). cTBS delivered on S1, in the real condition, produced a significant increase of STDT values from T0 to T1 ( $p<0.001$ ) and from T0 to T2 ( $p=0.008$ ) (black line, top left). Error bars indicate standard error. Asterisks indicate significant differences.

$p<0.01)$, time $\left(F_{(2,22)}=44.203 ; p<0.01\right)$, and side $\left(F_{(1,11)}=\right.$ 5.144; $p=0.044)$ and significant interactions of session $\times$ time $\left(F_{(4,44)}=56.713 ; p<0.01\right)$, session $\times$ side $\left(F_{(2,22)}=37.466 ; p<\right.$ $0.01)$, time $\times$ side $\left(F_{(2,22)}=33.930 ; p<0.01\right)$, and session $\times$ time $\times$ side $\left(F_{(4,44)}=33,321 ; p<0.01\right)$. The implication is that the effect of cTBS on STDT depends on a combination of the hand tested (left or right), the time after cTBS (T1 or T2 compared with T0), and the cortical site (S1 or S2) that was stimulated. Post hoc analyses showed that STDT values in the left hand significantly increased from T0 to T1 $(50.27 \pm 24.35$ vs $75.56 \pm$ 26.22; $p<0.001)$ and from T0 to T2 (50.27 \pm 24.35 vs $60.27 \pm$ 25.08; $p=0.008)$ after cTBS to S1. STDT measured in the right hand was unaffected. STDT did not show any changes in the S2 (Experiment 2) and sham (Experiment 3) sessions (Fig. 1). Baseline values of STDT did not show any differences among the three experiments (all $p$ values $>0.05$ ). The three-way ANOVA on STDT data obtained in Experiments 4 and 5 confirmed the findings of the first set of experiments, i.e., STDT increased only in the "real" condition and in the left index finger. There was a significant main effect of session $\left(F_{(1,9)}=9.906 ; p=0.012\right)$, time $\left(F_{(1,9)}=154.57 ; p<0.001\right)$, and side $\left(F_{(1,9)}=6.832 ; p=0.028\right)$ and significant interactions of session $X$ time $\left(F_{(1,9)}=102.26\right.$; $p<0.001)$, session $\times$ side $\left(F_{(1,9)}=48.303 ; p<0.001\right)$, time $\times$ side $\left(F_{(1,9)}=31.62 ; p<0.001\right)$, and session $\times$ time $\times$ side $\left(F_{(1,9)}\right.$ $=153.581 ; p<0.001)$. Post hoc analyses showed that STDT values in the left hand significantly increased from T0 to T1 (46.00 \pm 14.21 vs $63.66 \pm 16.14 ; p<0.001)$ after cTBS, whereas STDT did not change in other conditions (all $p$ values $>0.05$ ).

\section{Psychophysical method}

A standard psychophysical discrimination curve was constructed in all volunteers. The mean data are shown in Figure 2. cTBS to S1 reduced the slope of the curve, leading to an increase in PRT. However, there was no shift in the curve along the time $(x)$ axis and thus no significant change in PSE. RTs to decision onset were also increased by cTBS (Fig. 3), consistent with the increase in PRT.

Why did cTBS change STDT in the previous experiment yet had no effect on PSE here? The answer probably lies in methodology. In the ascending method, pairs of stimuli are applied with gradually increasing intervals. STDT is the interval when participants have successfully identified three successive pairs as separate stimuli. To achieve three successive correct answers, participants must have a high probability of being correct on each occasion. The psychophysical curve shows that, at intervals around STDT, cTBS reduces the probability of detecting two 


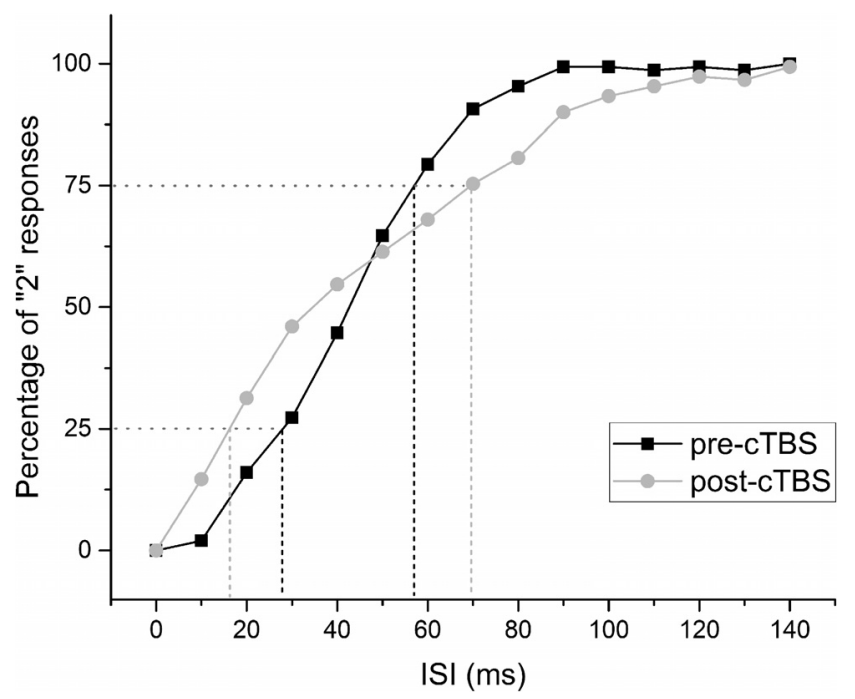

Figure 2. Psychometric curve representing the result of the behavioral task (Experiment 4). The horizontal dotted lines represent the probability of $25 \%$ and $75 \%$ of " 2 " responses on the $y$-axis (25p and 75p). The black dashed vertical lines represent the interval between $25 p$ and $75 p$ on the $x$-axis before cTBS, whereas the gray dashed vertical lines represent the interval between 25p and 75p after cTBS on the $x$-axis. Because the PRT can be calculated by the formula $(75 p-25 p) / 2$, the vertical dashed lines gives an idea about the effect of cTBS on PRT.

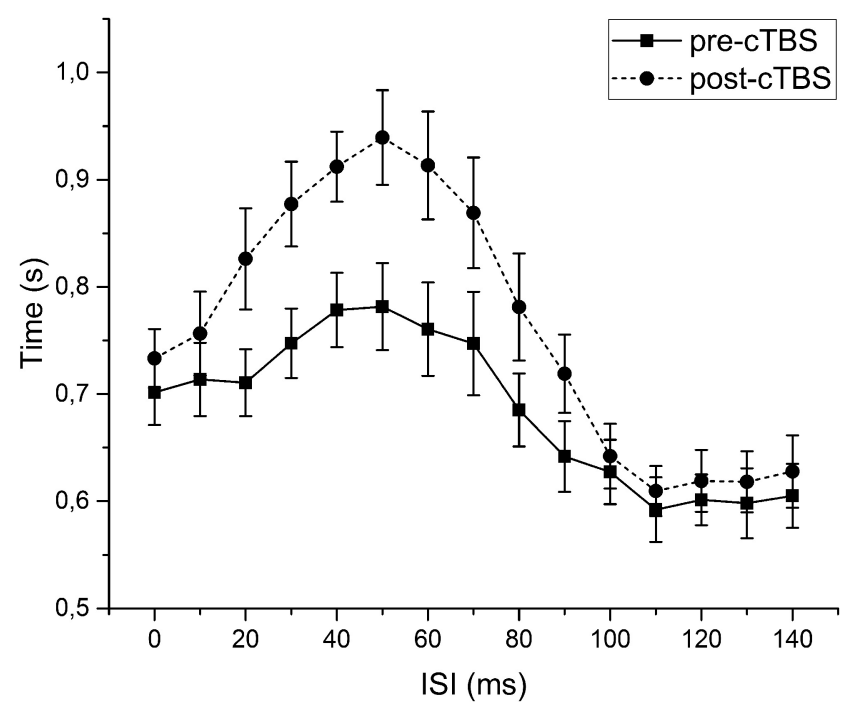

Figure 3. RTs. The continuous line represents RT before cTBS, whereas the dotted line shows RT after cTBS. Difference in RT at ISI between 30 and 90 ms are significant (see Results). Error bars indicate standard error.

stimuli. Thus, the ascending estimate of STDT will increase even when PSE of the psychophysical curve remains unchanged.

In the statistical analysis, the two-way ANOVA showed no significant main effects on PSE; in contrast, for PRT, there was a significant main effect of session $\left(F_{(1,9)}=53.190 ; p<0.001\right)$ and time $\left(F_{(1,9)}=28.205 ; p<0.001\right)$ and a significant interaction of session $\times$ time $\left(F_{(1,9)}=77.624 ; p<0.01 ;\right.$ Fig. 2$)$. Post hoc analyses showed that PRT values significantly increased from T0 to T1 in the real session $(8.96 \pm 2.07$ vs $21.26 \pm 5.86 \mathrm{~ms} ; p<0.001)$, whereas it was unchanged in the sham session. For RTs, the threeway ANOVA showed a significant main effect of session $\left(F_{(1,9)}=\right.$ $5.621 ; p=0.042)$, time $\left(F_{(1,9)}=18.756 ; p=0.002\right)$, and ISI $\left(F_{(14,126)}=18.551 ; p<0.001\right)$ and significant interactions of session $\times$ time $\left(F_{(1,9)}=15.594 ; p=0.003\right)$, session $\times$ ISI
$\left(F_{(2.387,21.487)}=4.967 ; p=0.013\right)$, time $\times$ ISI $\left(F_{(4.725,42.525)}=\right.$ $8.628 ; p<0.01)$, and session $\times$ time $\times \operatorname{ISI}\left(F_{(4.286,38.576)}=7.174\right.$; $p<0.01)$. Post hoc analyses showed that cTBS induced a significant increase in RT in ISI ranging from 30 to $90 \mathrm{~ms}$ (all $p$ values $<0.05$; Fig. 3), whereas RT did not change in the sham session. Pearson's correlation coefficient showed a significant baseline correlation between STDT and PSE $(r=0.779 ; p=0.00)$ and between STDT and PRT $(r=0.734 ; p=0.016)$.

\section{N20 latency and amplitude}

As reported previously (Conte et al., 2012), cTBS reduced the peak amplitude of the N20. The two-way repeated-measures ANOVA with time and session as main factors showed no main or interaction effects of cTBS on the latency of $\mathrm{N} 20$ (all $p$ values $>0.1$ ). Baseline values of $\mathrm{N} 20$ latency were the same in all experiments (all $p$ values $>0.05 ;$ Fig. 4 ). In contrast, cTBS over S1 had a clear effect on the amplitude of the N20. There was a significant main effect of session $\left(F_{(1,22)}=27.191 ; p<0.01\right)$ and time $\left(F_{(2,22)}\right.$ $=64.708 ; p<0.01)$ and a significant session $\times$ time interaction $\left(F_{(2,22)}=75.437 ; p<0.01\right)$. Post hoc comparisons showed that cTBS significantly reduced the N20 from baseline $(2.95 \pm 0.67$ $\mu \mathrm{V})$ to $\mathrm{T} 1(2.18 \pm 0.59 \mu \mathrm{V} ; p<0.01)$, and the decrease was still significant at T2 $(2.61 \pm 0.58 \mu \mathrm{V} ; p<0.01)$; there was no change in the $\mathrm{N} 20$ amplitude in the sham session (all $p$ values $>0.05$; Fig. 4). Again, baseline values of N20 amplitude were the same in all experiments (all $p$ values $>0.05$ ).

\section{N20 recovery cycle}

cTBS reduced the amount of N20 suppression in the recovery curve but only at the shortest interval of $5 \mathrm{~ms}$ (Fig. 5). This was confirmed statistically using a three-way repeated-measures ANOVA, which showed a significant main effect of session $\left(F_{(1,11)}=25.080 ; p<0.01\right)$, time $\left(F_{(2,22)}=32.037 ; p<0.01\right)$, and ISI $\left(F_{(2,22)}=20.590 ; p<0.01\right)$, with significant interactions of session $\times$ time $\left(F_{(2,22)}=36.636 ; p<0.01\right)$, session $\times \operatorname{ISI}\left(F_{(2,22)}\right.$ $=10.079 ; p=0.01)$, time $\times \operatorname{ISI}\left(F_{(4,44)}=27.584 ; p<0.01\right)$, and session $\times$ time $\times$ ISI $\left(F_{(4,44)}=26.926 ; p<0.01\right)$. The implication is that the effect of cTBS depended on a combination of the time after cTBS (T1 or T2 compared with T0), the ISI of the recovery cycle $(5,20,40 \mathrm{~ms})$, and whether real or sham stimulation was applied. Post hoc comparisons showed that, at R5, real cTBS significantly reduced the amount by which the second SEP was suppressed by the first SEP at an ISI of $5 \mathrm{~ms}$ (R5) from baseline to T1 $(0.51 \pm 0.22$ vs $0.69 \pm 0.21 ; p<0.01)$, and this reduction was still significant at $\mathrm{T} 2(0.51 \pm 0.22$ vs $0.59 \pm 0.21 ; p=0.01)$; in contrast, R5 did not change significantly in the sham session (all $p$ values $>0.05)$. R20 and R40 were unaffected by real or sham cTBS (all $p$ values $>0.05$ ).

\section{e-HFO and 1-HFO}

cTBS had opposite effects on e-HFO and l-HFO, i.e., it increased e-HFO and reduced l-HFO. In the statistics, a two-way repeated-measures ANOVA on e-HFO area showed a significant main effect of session $\left(F_{(1,11)}=30.852 ; p<0.01\right)$ and time $\left(F_{(2,22)}=47.270 ; p<0.01\right)$ and a significant session $\times$ time interaction $\left(F_{(2,22)}=44.924 ; p<0.01\right)$. Post hoc comparisons showed that cTBS significantly increased e-HFO from baseline to $\mathrm{T} 1(2.95 \pm 1.20$ vs $3.72 \pm 1.36$; $p<0.01$; Fig. 6$)$, and the increase was still significant at T2 $(2.95 \pm 1.20$ vs $3.22 \pm 1.25 ; p<0.01$ ), whereas e-HFO did not change in the sham session (all $p$ values $<0.05$ ).

For l-HFO, there was a significant main effect of session $\left(F_{(1,11)}=17.276 ; p<0.05\right)$ and time $\left(F_{(2,22)}=17.715 ; p<0.01\right)$ 


\section{N20}

S1-cTBS

Sham

\section{LATENCY}

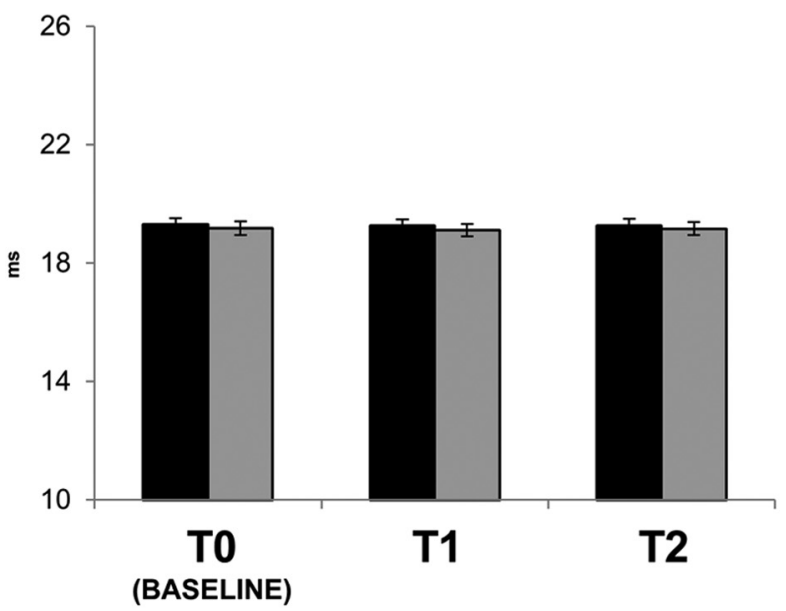

AMPLITUDE

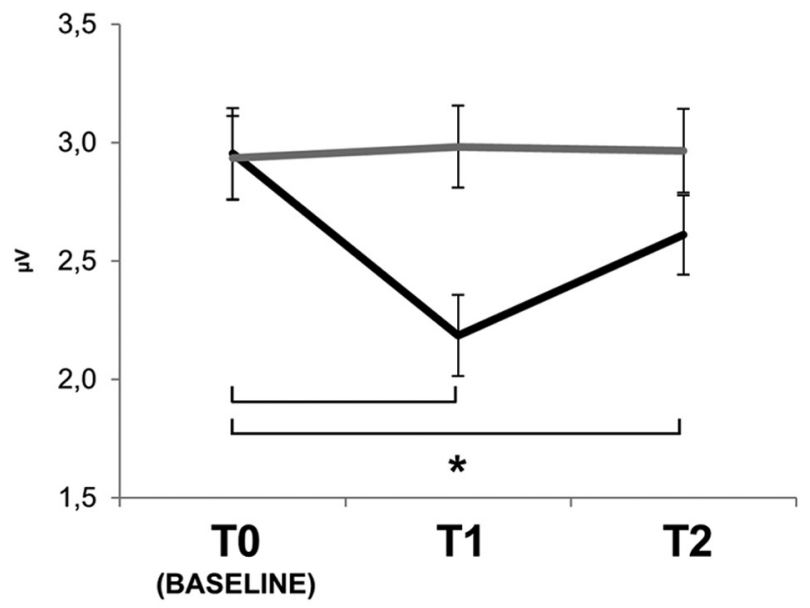

Figure 4. N20 latency (left) and amplitude (right) before (T0), immediately after (T1), and $30 \mathrm{~min}$ after (T2) real (black lines) and sham (gray lines) cTBS over S1. cTBS delivered on S1, in the real condition, produced a significant decrease of N20 amplitude from T0 to T1 $(p<0.01)$ and from T0 to T2 $(p<0.01)$ (black line, right).

\section{N20 RECOVERY CYCLE}

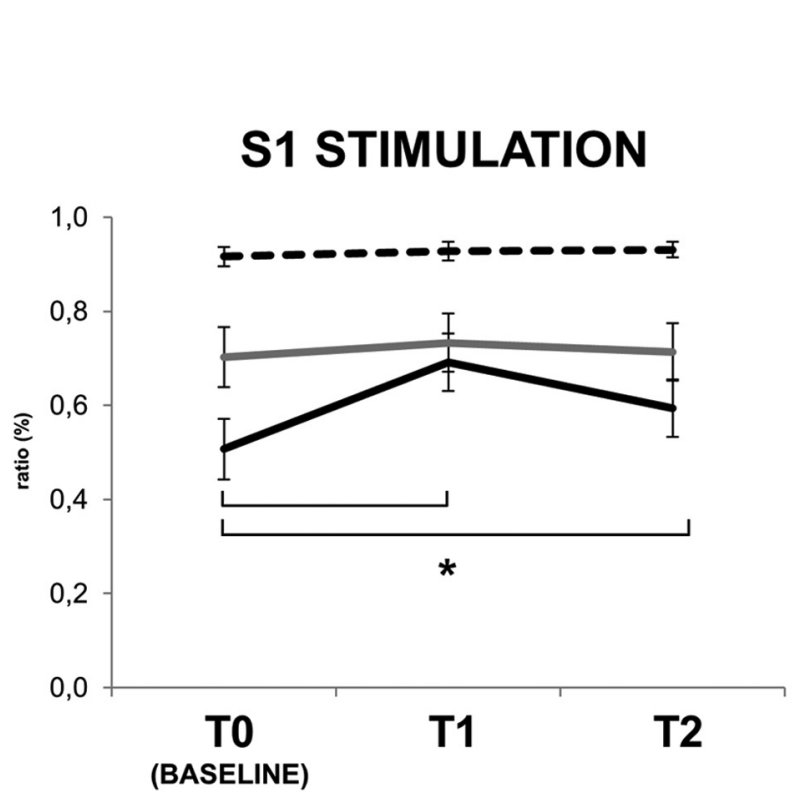

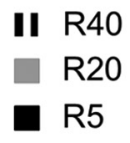

R5

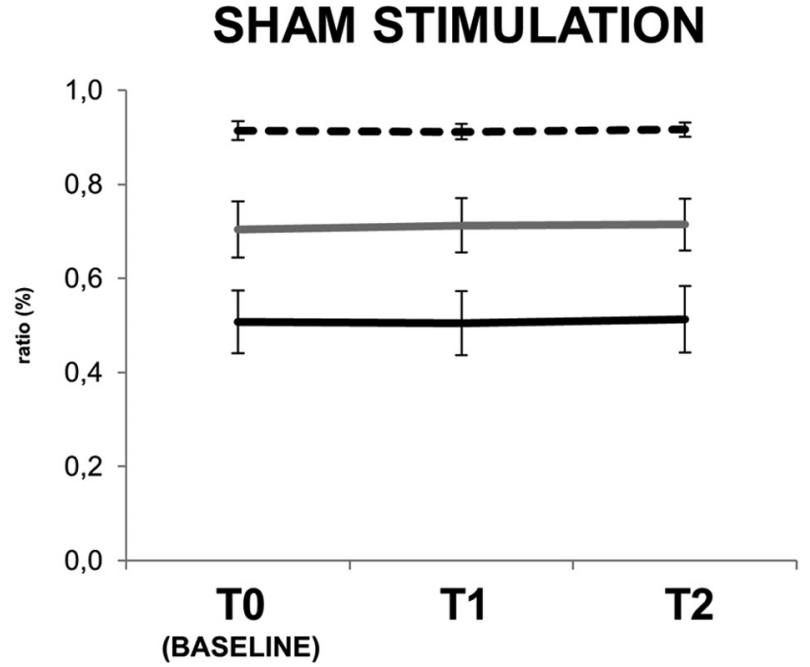

Figure 5. N20 recovery cycle at ISI of $5 \mathrm{~ms}$ (R5; black line), $20 \mathrm{~ms}$ (R20; gray line), and $40 \mathrm{~ms}$ (R40; dashed line) before (T0), immediately after (T1), and 30 min after (T2) real (left) and sham (right) CTBS over S1. cTBS delivered on S1, in the real condition, produced a significant increase of R5 from T0 to T1 $(p<0.01)$ and from T0 to T2 ( $p<0.01)$ (black line, left). Error bars indicate standard error. Asterisks indicate significant differences.

and a significant session $\times$ time interaction $\left(F_{(2,22)}=15.035 ; p<\right.$ $0.01)$. Post hoc comparisons showed that cTBS significantly decreased l-HFO from baseline to T1 $(3.22 \pm 1.34$ vs $2.05 \pm 0.54$; $p=0.003)$, and the decrease was still significant at T2 (3.22 \pm 1.34 vs $2.64 \pm 1.01 ; p=0.01$; Fig. 6 , right column), whereas 1 -HFO did not change in the sham session (all $p$ values $>0.05$ ).
Correlation between the effect of cTBS on STDT, N20 recovery cycle, and $\mathrm{HFO}$

At baseline (i.e., T0), there was a significant correlation between STDT and R5 $(r=0.824 ; p<0.01)$, between STDT and 1-HFO area $(r=-0.835 ; p<0.01)$, and between R5 and 1-HFO area $(r=-0.654 ; p=0.021$; data not illustrated). There was no sig- 

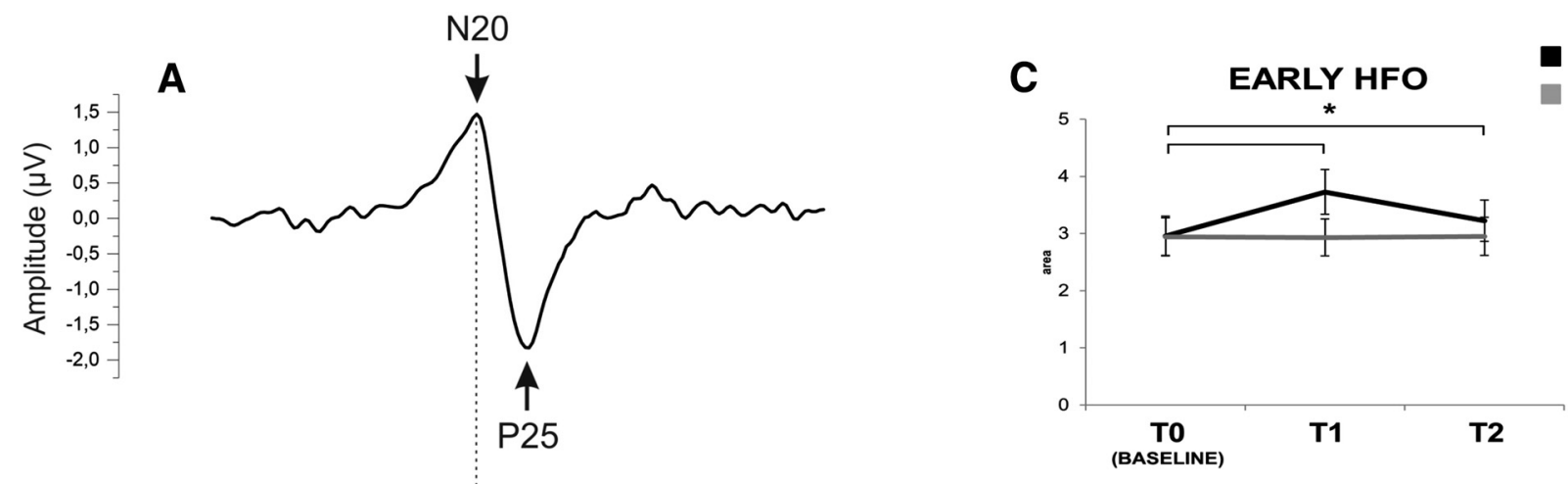

S1-cTBS

Sham
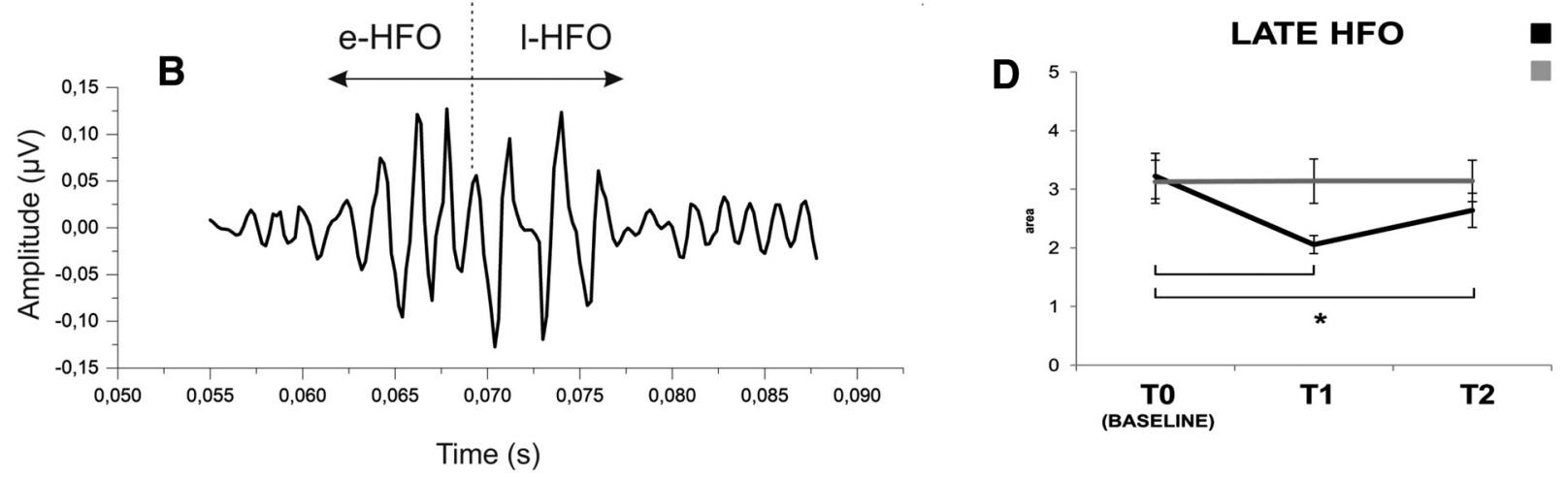

Figure 6. Left column, A wide-band SEP showing the N20 -P25 complex ( $\boldsymbol{A}$ ) and the same recording bandpass filtered between 400 and $800 \mathrm{~Hz}$ showing HFO (B) in one of the subjects. As shown, e-HFO and I-HFO can be divided by the N20 peak. The average starts $5 \mathrm{~ms}$ after the stimulation artifact, which was removed manually. Right column, e-HF0 (C) and I-HF0 (D) area before (T0), immediately after (T1), and 30 min after (T2) real (gray line) and sham (black line) CTBS over S1. cTBS delivered on S1, in the real condition, produced a significant increase in e-HF0 area from T0 to $\mathrm{T} 1(p<0.01)$ and from T0 to T2 $(p<0.01)$ (black line, left) and a decrease in I-HF0 area from T0 to T1 ( $p=0.003)$ and from T0 to T2 ( $p=0.01)$ (black line, right). HF0 area is expressed in $\mu V^{2}$ $\times 10^{-4}$. Error bars indicate standard error. Asterisks indicate significant differences.

nificant baseline correlation between STDT, R20, R40, and e-HFO (all $p$ values $>0.05$ ). In addition, the changes induced by cTBS in STDT were significantly correlated with the changes induced by cTBS in R5, and this was true at T1 $(r=0.745 ; p<0.01)$ and T2 $(r=0.660 ; p<0.05$; Fig. 7 , top row). There was also a significant correlation with the changes induced by cTBS in l-HFO area, at both T1 $(r=-0.895 ; p<0.01)$ and T2 $(r=$ $-0.886 ; p<0.01$; Fig. 7 , bottom row), and between the changes induced in R5 and those in $1-\mathrm{HFO}$ at T1 $(r=-0.762 ; p=0.004)$ and T2 $(r=-0.681 ; p=0.015$; data not shown $)$.

\section{SEP N120 component}

The two-way repeated-measures ANOVA of the effect of cTBS on N120 showed a significant main effect of time $\left(F_{(2,22)}=67.399\right.$; $p<0.01)$ and electrode $\left(\mathrm{T} 3, \mathrm{~T} 4 ; F_{(1,11)}=49.336 ; p<0.01\right)$ and a significant time $\times$ electrode interaction $\left(F_{(2,22)}=41.433 ; p<\right.$ $0.01)$. Post hoc comparisons showed that cTBS significantly reduced N120 amplitude at the right temporal electrode (T4) from baseline to $\mathrm{T} 1(2.31 \pm 0.66$ vs $1.81 \pm 0.56 ; p<0.01)$, and the decrease was still significant at T2 $(2.31 \pm 0.66$ vs $2.07 \pm 0.59 ; p<$ 0.01 ; Fig. 8), whereas N120 did not change significantly at the left temporal electrode (T3; $p>0.05)$.

\section{Discussion}

The present data confirm that cTBS over S1 increases STDT measured by an ascending method. The change correlates with reduced paired-pulse N20 suppression and reduced 1-HFO area. Both of these are putative markers of S1 inhibition, which we argue can sharpen temporal information processing. Thus, re- duced inhibition after cTBS will lead to greater temporal uncertainty. As expected, this leads to increased uncertainty in decision making, reflected as both a reduction in slope of the psychophysical discrimination curve and an increased RT. We conclude that cTBS over S1 has an effect similar to adding noise to neural processing and that this is caused by reduced excitability of intrinsic inhibitory systems. cTBS delivered over S2 had no effect on STDT, suggesting that it plays a minimal role in this task.

Our procedures avoided some possible confounding factors. Similar baseline STDT values over the three sessions excludes a possible learning effect. Bias attributable to a lack of attention was excluded using catch trials (Conte et al., 2010, 2012). The neuronavigation system minimized errors in coil positioning attributable to individual anatomical variations (Conte et al., 2012). However, given the lack of spatial specificity of TMS, it is not possible to determine which subareas within S1 and S2 were the likely sites of action. Cutaneous afferents project to areas $3 \mathrm{~b}$ and 1 within S1 (Ozaki and Hashimoto, 2011). Because area 3b is located deep in the posterior bank of the central sulcus, it is likely that the observed effects are mostly attributable to stimulation of the more superficial area 1. In humans, S2 contains at least three distinct somatosensory fields, called OP1, OP3, and OP4 (Eickhoff et al., 2007). Based on previously published coordinates, it is likely that our TMS protocol targeted an area between OP1 and OP4 (Eickhoff et al., 2007).

Previous work has shown that both single-pulse TMS (Hannula et al., 2008; Bolognini et al., 2010) and offline cTBS (present data; Conte et al., 2012, 2014) could both increase STDT. The 


\section{CTBS-INDUCED CHANGES CORRELATIONS}

T1
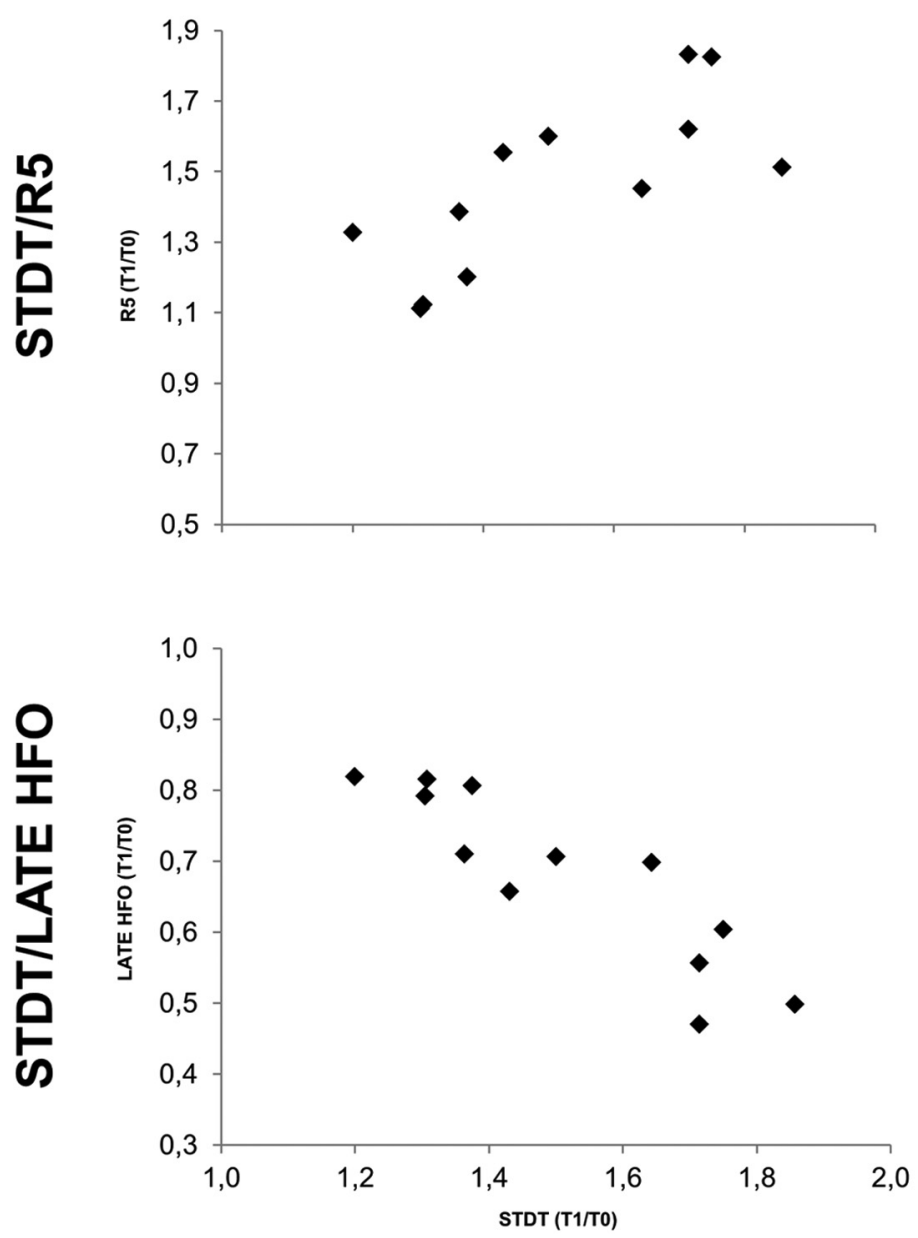

T2
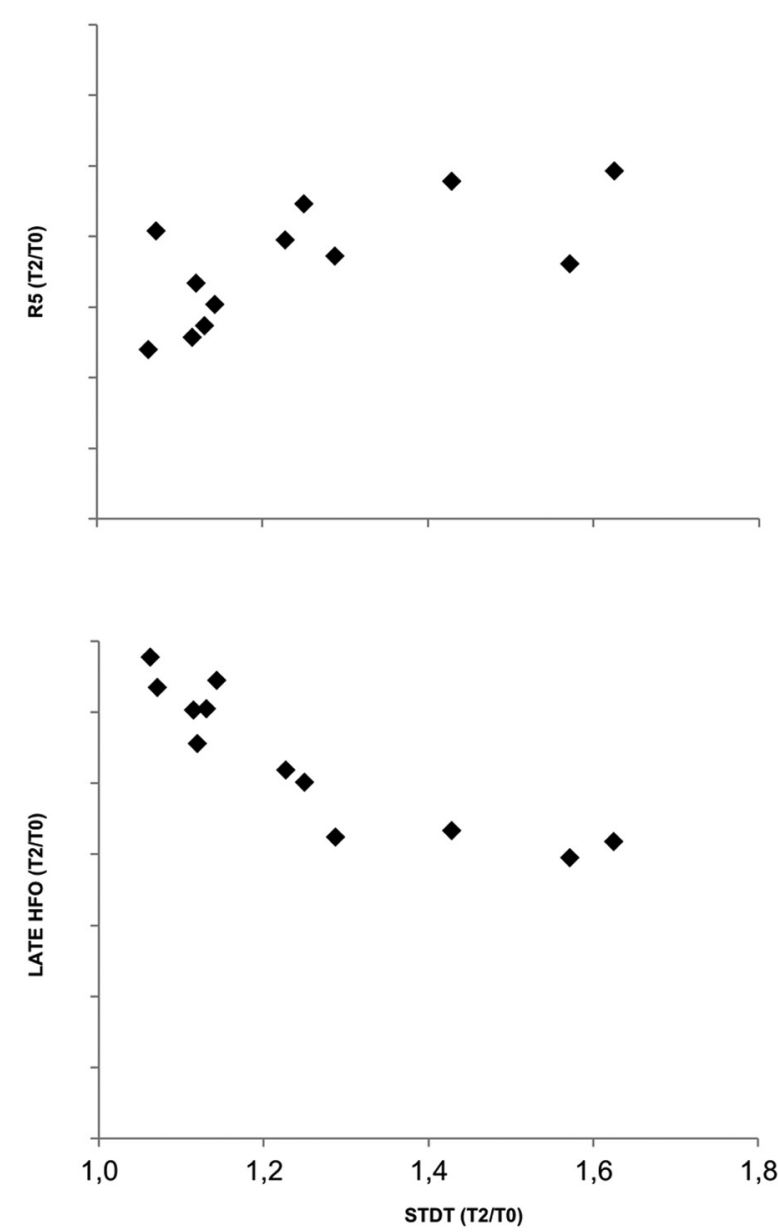

Figure 7. Correlations between STDT and R5 (top row) and between STDT and I-HFO (bottom row) after cTBS on S1; TO/T1 ratio (left column) and T0/T2 ratio (right column). Changes in STDT induced by cTBS delivered over $\mathrm{S} 1$ were significantly correlated with the changes induced on R5 and on I-HF0 at T1 and T2.

question we ask here is whether this behavioral effect is related to effects on neural processing in S1. Three lines of evidence suggest that it was.

As described by others (Conte et al., 2012), cTBS reduced the amplitude of the unconditioned N20. Because the N20 is thought to be generated by EPSPs in the apical dendrites of somatosensory pyramidal neurons, caused by excitatory input from the thalamus (Hashimoto et al., 1996), then cTBS presumably reduced the excitability of these neurons or presynaptically suppressed the input fibers.

The PP-SEP findings were new. cTBS reduced the amount by which the second SEP of a pair was suppressed by the first. This was significant at ISI of $5 \mathrm{~ms}$ but not at 20 or $40 \mathrm{~ms}$. The effect is unlikely to be a consequence of the smaller unconditioned N20 because previous studies showed that N20 amplitude did not significantly influence PP-SEP suppression (Gatica Tossi et al., 2013; Höffken et al., 2013). Several mechanisms can contribute to PP-SEP suppression. Work on healthy subjects (Schwartz and Shagass, 1964; Emori et al., 1991) and on neurological patients with cortical hyperexcitability (Ugawa et al., 1996; Frasson et al., 2001; Mochizuki et al., 2001; Valeriani et al., 2005) suggested that
N20 suppression, particularly at short ISI, mainly takes place in S1. In contrast, inhibition at longer ISI may involve the dorsal column nuclei (Lüders et al., 1984) or thalamus (Höffken et al., 2010). This could explain why cTBS only affected paired-pulse suppression at $5 \mathrm{~ms}$ ISI because suppression at later intervals could involve non-cortical mechanisms that were unaffected by cTBS.

Although not directly tested, there is some evidence that paired-pulse inhibition in the cortex may rely on GABAergic transmission (Deisz and Prince, 1989; Mennerick and Zorumski, 1995; Huttunen et al., 2008). In the motor cortex, cTBS is known to reduce the excitability of GABAergic inhibition (in the paradigm of short-interval intracortical inhibition; Huang et al., 2005). Thus, if cTBS had the same effect in S1, it might explain why it reduced PP-SEP suppression.

As described in a previous report (Katayama et al., 2010), cTBS over S1 reduced l-HFO area and increased e-HFO area. Several lines of evidence suggest that e-HFO represent highfrequency activity from thalamocortical fibers projecting mainly to area $3 \mathrm{~b}$ and 1 within S1. If so, it is unclear why cTBS would increase their area. Previous work has shown changes in excitabil- 


\section{N120}

Right (T4)
Left (T3)

AMPLITUDE

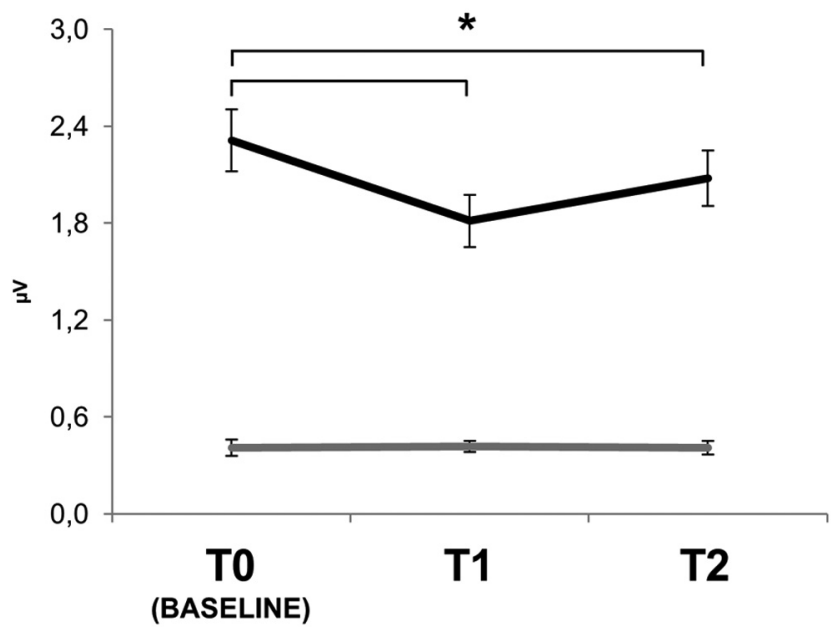

Figure 8. Right (T4, black line) and left ( $\mathrm{T} 3$, gray line) $\mathrm{N} 120$ amplitude before (T0), immediately after (T1), and $30 \mathrm{~min}$ after (T2) CTBS delivered on the right S2. S2- CTBS produced a significant decrease of right $\mathrm{N} 120$ amplitude, recorded at $\mathrm{T} 4$, from $\mathrm{T} 0$ to $\mathrm{T} 1(p<0.01)$ and from T0 to T2 $(p<0.01)$. Error bars indicate standard error. Asterisks indicate significant differences.

ity of areas distant from the site of cortical stimulation (Hubl et al., 2008; Stefan et al., 2008; Cárdenas-Morales et al., 2011). In this view, assuming a thalamic generator for e-HFO, we speculate that the increase in e-HFO area is attributable to a reduction in activity of corticothalamic projections that normally reduce oscillatory activity.

1-HFO are thought to represent postsynaptic activity of inhibitory interneurons in S1 (Hashimoto et al., 1996; Klostermann et al., 2001; Curio, 2000; Jones et al., 2000; Ozaki et al., 2001; Ikeda et al., 2002; Gobbelé et al., 2004; Ozaki and Hashimoto, 2011). Specifically, human studies suggest that l-HFO might reflect the activity of inhibitory interneurons that produce feedforward inhibition of pyramidal neurons (Ozaki and Hashimoto, 2011). Our data do not address this point, but they do show a clear correlation between the baseline and post-cTBS values of 1-HFO area, STDT, and the degree of inhibition of PP-SEP at $5 \mathrm{~ms} \mathrm{ISI,}$ suggesting that the three variables share common mechanisms. We propose that the inhibitory circuits that generate l-HFO are the same that, because of feedforward inhibition, sharpen the distinction between potentially overlapping excitatory inputs between the first and second afferent volley in STDT. Moreover, this inhibitory mechanism may also be responsible for the suppression PP-SEP at $5 \mathrm{~ms}$ ISI.

Why is there a correlation between STDT values and PP-SEP inhibition at $5 \mathrm{~ms}$ but not at longer ISI? It seems likely to result from the fact that feedforward inhibition interacts with both the initial input that caused it and subsequent inputs. Feedforward inhibition rapidly terminates initial excitatory action, sharpening up its temporal profile; in addition, it reduces the amplitude of other inputs that arrive a short time later. The first effect is important for STDT because it will prevent prolonged discharge from the first stimulus from interfering with perception of the second. The second effect is measured by the $5 \mathrm{~ms}$ PP-SEP, which examines very short-latency interactions between successive stimuli. As noted above, SEP suppression at longer PP-SEP intervals is thought to be caused by other mechanisms that do not interact with the initial input that caused them. Note that STDT (normally $\sim 60 \mathrm{~ms}$ ) need not directly reflect the duration of the short-lasting feedforward inhibitory effect. There are many steps between initial processing and perception that can distort this relationship. Finally, it is interesting to note that Tamura et al. (2008) found that the longer STDT in patients with dystonia was inversely correlated with PP-SEP suppression of the P27 component at ISI of $5 \mathrm{~ms}$ but not at longer intervals. We did not measure P27 in the present study. However, the amplitude of the N20 was calculated as the peak-to-peak difference between N20 and P25, which probably captures a similar effect after CTBS on PP-SEP at ISI of $5 \mathrm{~ms}$.

cTBS applied over S2 did not change STDT, although it reduced the amplitude of the N120 component of SEP recorded contralateral to median nerve stimulation (T4; García-Larrea et al., 1995). Thus, it seems that, although cTBS could reduce the excitability of S2, it had no effect on STDT, implying that S2 does not play a critical role in STDT. In a flutter discrimination task, the firing rate of neurons in S1 varies significantly as a function of stimulation frequency (Salinas et al., 2000), whereas discharge of S2 neurons is more related to the difference between frequencies (Romo et al., 2002; Romo and Salinas, 2003). Therefore, S2 may play little role in STDT because STDT does not entail a comparison between afferent stimuli but instead requires detection of a gap between two stimuli.

These arguments suggest that reduced feedforward inhibition of sensory input to S1 reduces the temporal certainty of incoming information and that this increases the difficulty of the STDT task. To examine this in more detail, we explored STDT using a psychophysical approach. The results showed that the slope of the discrimination curve was reduced and that the RT to decision making increased. These effects are compatible with reduced certainty in signal processing, consistent with our hypothesis. They are also consistent with previous studies that demonstrated that TMS can increase neural "noise" within the stimulated area ( $\mathrm{Ru}$ zzoli et al., 2010; Teo et al., 2011). In contrast, PSE was not changed after cTBS over S1, indicating that the internal boundary, or criterion used by subjects to classify the responses, remained the same.

In summary, the present data show that there is a correlation between STDT, SEP recovery cycle, and l-HFO area. These findings strongly suggest that the ability to temporally discriminate two distinct afferent stimuli relies on inhibitory mechanisms in $\mathrm{S} 1$ and hence that STDT may in fact represent a direct behavioral correlate of inhibition in S1. These results shed additional light on human somatosensory physiology and could prompt future therapeutic approaches in neurological diseases characterized by impairment of cortical inhibitory mechanisms, such as dystonia (Tamura et al., 2008; Scontrini et al., 2009; Conte et al., 2014).

\section{References}

Artieda J, Pastor MA, Lacruz F, Obeso JA (1992) Temporal discrimination is abnormal in Parkinson's disease. Brain 115:199-210. CrossRef Medline

Boakye M, Huckins SC, Szeverenyi NM, Taskey BI, Hodge CJ Jr (2000) Functional magnetic resonance imaging of somatosensory cortex activity produced by electrical stimulation of the median nerve or tactile stimulation of the index finger. J Neurosurg 93:774-783. CrossRef Medline

Bolognini N, Papagno C, Moroni D, Maravita A (2010) Tactile temporal processing in the auditory cortex. J Cogn Neurosci 22:1201-1211. CrossRef Medline 
Cárdenas-Morales L, Grön G, Kammer T (2011) Exploring the after-effects of theta burst magnetic stimulation on the human motor cortex: a functional imaging study. Hum Brain Mapp 32:1948-1960. CrossRef Medline

Conte A, Modugno N, Lena F, Dispenza S, Gandolfi B, Iezzi E, Fabbrini G, Berardelli A (2010) Subthalamic nucleus stimulation and somatosensory temporal discrimination in Parkinson's disease. Brain 133:26562663. CrossRef Medline

Conte A, Rocchi L, Nardella A, Dispenza S, Scontrini A, Khan N, Berardelli A (2012) Theta-burst stimulation-induced plasticity over primary somatosensory cortex changes somatosensory temporal discrimination in healthy humans. PLoS One 7:e32979. CrossRef Medline

Conte A, Khan N, Defazio G, Rothwell JC, Berardelli A (2013) Pathophysiology of somatosensory abnormalities in Parkinson disease. Nat Rev Neurol 9:687-697. CrossRef Medline

Conte A, Rocchi L, Ferrazzano G, Leodori G, Bologna M, Li Voti P, Nardella A, Berardelli A (2014) Primary somatosensory cortical plasticity and tactile temporal discrimination in focal hand dystonia. Clin Neurophysiol 125:537-543. CrossRef Medline

Cruccu G, Aminoff MJ, Curio G, Guerit JM, Kakigi R, Mauguiere F, Rossini PM, Treede RD, Garcia-Larrea L (2008) Recommendations for the clinical use of somatosensory-evoked potentials. Clin Neurophysiol 119: 1705-1719. CrossRef Medline

Curio G (2000) Linking 600-Hz "spikelike" EEG/MEG wavelets ("sigmabursts") to cellular substrates: concepts and caveats. J Clin Neurophysiol 17:377-396. CrossRef Medline

Deisz RA, Prince DA (1989) Frequency-dependent depression of inhibition in guinea-pig neocortex in vitro by GABAB receptor feed-back on GABA release. J Physiol 412:513-541. CrossRef Medline

Eickhoff SB, Grefkes C, Zilles K, Fink GR (2007) The somatotopic organization of cytoarchitectonic areas on the human parietal operculum. Cereb Cortex 17:1800-1811. CrossRef Medline

Emori T, Yamada T, Seki Y, Yasuhara A, Ando K, Honda Y, Leis AA, Vachatimanont P (1991) Recovery functions of fast frequency potentials in the initial negative wave of median SEP. Electroencephalogr Clin Neurophysiol 78:116-123. CrossRef Medline

Frasson E, Priori A, Bertolasi L, Mauguière F, Fiaschi A, Tinazzi M (2001) Somatosensory disinhibition in dystonia. Mov Disord 16:674-682. CrossRef Medline

García-Larrea L, Lukaszewicz AC, Mauguière F (1995) Somatosensory responses during selective spatial attention: The N120-to-N140 transition. Psychophysiology 32:526-537. CrossRef Medline

Gatica Tossi MA, Lillemeier AS, Dinse HR (2013) Influence of stimulation intensity on paired-pulse suppression of human median nerve somatosensory evoked potentials. Neuroreport 24:451-456. CrossRef Medline

Gobbelé R, Waberski TD, Simon H, Peters E, Klostermann F, Curio G, Buchner H (2004) Different origins of low- and high-frequency components $(600 \mathrm{~Hz})$ of human somatosensory evoked potentials. Clin Neurophysiol 115:927-937. CrossRef Medline

Hannula H, Neuvonen T, Savolainen P, Tukiainen T, Salonen O, Carlson S, Pertovaara A (2008) Navigated transcranial magnetic stimulation of the primary somatosensory cortex impairs perceptual processing of tactile temporal discrimination. Neurosci Lett 437:144-147. CrossRef Medline

Hashimoto I, Mashiko T, Imada T (1996) Somatic evoked high-frequency magnetic oscillations reflect activity of inhibitory interneurons in the human somatosensory cortex. Electroencephalogr Clin Neurophysiol 100: 189-203. CrossRef Medline

Herwig U, Schönfeldt-Lecuona C, Wunderlich AP, von Tiesenhausen C, Thielscher A, Walter H, Spitzer M (2001) The navigation of transcranial magnetic stimulation. Psychiatry Res 108:123-131. CrossRef Medline

Höffken O, Lenz M, Tegenthoff M, Schwenkreis P (2010) Multichannel SEP-recording after paired median nerve stimulation suggests origin of paired-pulse inhibition rostral of the brainstem. Neurosci Lett 468:308311. CrossRef Medline

Höffken O, Tannwitz J, Lenz M, Sczesny-Kaiser M, Tegenthoff M, Schwenkreis P (2013) Influence of parameter settings on paired-pulsesuppression in somatosensory evoked potentials: a systematic analysis. Clin Neurophysiol 124:574-580. CrossRef Medline

Huang YZ, Edwards MJ, Rounis E, Bhatia KP, Rothwell JC (2005) Theta burst stimulation of the human motor cortex. Neuron 45:201-206. CrossRef Medline

Hubl D, Nyffeler T, Wurtz P, Chaves S, Pflugshaupt T, Lüthi M, von Wartburg R, Wiest R, Dierks T, Strik WK, Hess CW, Müri RM (2008) Time course of blood oxygenation level-dependent signal response after theta burst transcranial magnetic stimulation of the frontal eye field. Neuroscience 151:921-928. CrossRef Medline

Huttunen J, Pekkonen E, Kivisaari R, Autti T, Kähkönen S (2008) Modulation of somatosensory evoked fields from SI and SII by acute GABA A-agonism and paired-pulse stimulation. Neuroimage 40:427-434. CrossRef Medline

Ikeda H, Leyba L, Bartolo A, Wang Y, Okada YC (2002) Synchronized spikes of thalamocortical axonal terminals and cortical neurons are detectable outside the pig brain with MEG. J Neurophysiol 87:626-630. Medline

Jones MS, MacDonald KD, Choi B, Dudek FE, Barth DS (2000) Intracellular correlates of fast $(>200 \mathrm{~Hz})$ electrical oscillations in rat somatosensory cortex. J Neurophysiol 84:1505-1518. Medline

Katayama T, Suppa A, Rothwell JC (2010) Somatosensory evoked potentials and high frequency oscillations are differently modulated by theta burst stimulation over primary somatosensory cortex in humans. Clin Neurophysiol 121:2097-2103. CrossRef Medline

Klem GH, Lüders HO, Jasper HH, Elger C (1999) The ten-twenty electrode system of the International Federation. The International Federation of Clinical Neurophysiology. Electroencephalogr Clin Neurophysiol Suppl 52:3-6. Medline

Klostermann F, Nolte G, Curio G (2001) Independent short-term variability of spike-like $(600 \mathrm{~Hz})$ and postsynaptic (N20) cerebral SEP components. Neuroreport 12:349-352. CrossRef Medline

Lacruz F, Artieda J, Pastor MA, Obeso JA (1991) The anatomical basis of somaesthetic temporal discrimination in humans. J Neurol Neurosurg Psychiatr 54:1077-1081. CrossRef Medline

Lockwood PL, Iannetti GD, Haggard P (2013) Transcranial magnetic stimulation over human secondary somatosensory cortex disrupts perception of pain intensity. Cortex 49:2201-2209. CrossRef Medline

Lüders H, Lesser R, Gurd A, Klem G (1984) Recovery functions of spinal cord and subcortical somatosensory evoked potentials to posterior tibial nerve stimulation: intrasurgical recordings. Brain Res 309:27-34. CrossRef Medline

Mendez JC, Prado L, Mendoza G, Merchant H (2011) Temporal and spatial categorization in human and non-human primates. Front Integr Neurosci 5:50. CrossRef Medline

Mennerick S, Zorumski CF (1995) Paired-pulse modulation of fast excitatory synaptic currents in microcultures of rat hippocampal neurons. J Physiol 488:85-101. CrossRef Medline

Meyer-Hardting E, Wiederholt WC, Budnick B (1983) Recovery function of short-latency components of the human somatosensory evoked potential. Arch Neurol 40:290-293. CrossRef Medline

Mochizuki H, Hanajima R, Kowa H, Motoyoshi Y, Ashida H, Kamakura K, Motoyoshi K, Ugawa Y (2001) Somatosensory evoked potential recovery in myotonic dystrophy. Clin Neurophysiol 112:793-799. CrossRef Medline

Murakami T, Sakuma K, Nomura T, Nakashima K, Hashimoto I (2008) High-frequency oscillations change in parallel with short-interval intracortical inhibition after theta burst magnetic stimulation. Clin Neurophysiol 119:301-308. CrossRef Medline

Oldfield RC (1971) The assessment and analysis of handedness: the Edinburgh inventory. Neuropsychologia 9:97-113. CrossRef Medline

Ozaki I, Hashimoto I (2011) Exploring the physiology and function of highfrequency oscillations (HFOs) from the somatosensory cortex. Clin Neurophysiol 122:1908-1923. CrossRef Medline

Ozaki I, Yaegashi Y, Kimura T, Baba M, Matsunaga M, Hashimoto I (2001) Dipole orientation differs between high frequency oscillations and N20m current sources in human somatosensory evoked magnetic fields to median nerve stimulation. Neurosci Lett 310:41-44. CrossRef Medline

Pastor MA, Day BL, Macaluso E, Friston KJ, Frackowiak RS (2004) The functional neuroanatomy of temporal discrimination. J Neurosci 24: 2585-2591. CrossRef Medline

Rocchi L, Conte A, Nardella A, Li Voti P, Di Biasio F, Leodori G, Fabbrini G, Berardelli A (2013) Somatosensory temporal discrimination threshold may help to differentiate patients with multiple system atrophy from patients with Parkinson's disease. Eur J Neurol 20:714-719. CrossRef Medline

Romo R, Salinas E (2003) Flutter discrimination: neural codes, perception, memory and decision making. Nat Rev Neurosci 4:203-218. CrossRef Medline 
Romo R, Hernández A, Zainos A, Lemus L, Brody CD (2002) Neuronal correlates of decision-making in secondary somatosensory cortex. Nat Neurosci 5:1217-1225. CrossRef Medline

Ruzzoli M, Marzi CA, Miniussi C (2010) The neural mechanisms of the effects of transcranial magnetic stimulation on perception. J Neurophysiol 103:2982-2989. CrossRef Medline

Salinas E, Hernandez A, Zainos A, Romo R (2000) Periodicity and firing rate as candidate neural codes for the frequency of vibrotactile stimuli. J Neurosci 20:5503-5515. Medline

Sandrini M, Rossini PM, Miniussi C (2008) Lateralized contribution of prefrontal cortex in controlling task-irrelevant information during verbal and spatial working memory tasks: rTMS evidence. Neuropsychologia 46:2056-2063. CrossRef Medline

Schwartz M, Shagass C (1964) Recovery functions of human somatosensory and visual evoked potentials. Ann N Y Acad Sci 112:510-525. Medline

Scontrini A, Conte A, Defazio G, Fiorio M, Fabbrini G, Suppa A, Tinazzi M, Berardelli A (2009) Somatosensory temporal discrimination in patients with primary focal dystonia. J Neurol Neurosurg Psychiatr 80:1315-1319. CrossRef Medline

Stefan K, Gentner R, Zeller D, Dang S, Classen J (2008) Theta-burst stimu- lation: remote physiological and local behavioral after-effects. Neuroimage 40:265-274. CrossRef Medline

Tamura Y, Matsuhashi M, Lin P, Ou B, Vorbach S, Kakigi R, Hallett M (2008) Impaired intracortical inhibition in the primary somatosensory cortex in focal hand dystonia. Mov Disord 23:558-565. CrossRef Medline

Teo JT, Swayne OB, Cheeran B, Greenwood RJ, Rothwell JC (2011) Human $\theta$ burst stimulation enhances subsequent motor learning and increases performance variability. Cereb Cortex 21:1627-1638. CrossRef Medline

Ugawa Y, Genba-Shimizu K, Kanazawa I (1996) Somatosensory evoked potential recovery (SEP-R) in various neurological disorders. Electroencephalogr Clin Neurophysiol 100:62-67. CrossRef Medline

Valeriani M, Ranghi F, Giaquinto S (2003) The effects of aging on selective attention to touch: a reduced inhibitory control in elderly subjects? Int J Psychophysiol 49:75-87. CrossRef Medline

Valeriani M, Rinalduzzi S, Vigevano F (2005) Multilevel somatosensory system disinhibition in children with migraine. Pain 118:137-144. CrossRef Medline

Vollono C, Ferraro D, Miliucci R, Vigevano F, Valeriani M (2010) The abnormal recovery cycle of somatosensory evoked potential components in children with migraine can be reversed by topiramate. Cephalalgia 30 : 17-26. CrossRef Medline 